\title{
Economic sustainability in Short Food Supply Chain. The case of the Horizon 2020 project "Short Food Supply Chain Knowledge and Innovation Network (SKIN) '”*
}

\author{
by Gianluigi De Pascale ${ }^{* *}$,Fedele Colantuono***, Sara Djelveh ${ }^{* * * *}$ \\ and Francesco Conto ${ }^{* * * * *}$
}

\begin{abstract}
This study aims at providing a framework to find out best agro-food practices and foster their spreading to European actors operating in Short Food Supply Chain (SFSC). Quick knowledge circulation allows a reduction of asymmetric information among such operators. These latter frequently imply an excessive level of transactional costs that negatively affect farms economic sustainability. Hence, reduction of costs is an important priority. The methodological approach is carried out within the SKIN project, analyzing metrics parameters to assess SFSC economic sustainability. It will create local hubs to collect knowledge from each European area where stakeholders operate, through the identification of adequate regional nodes, connected among themselves. Network will enable a real knowledge transfer and innovation uptake. Lastly, the network will be exploited to enhance the added value of involved farms.
\end{abstract}

Key words: economic sustainability, best practices, short food supply chain, SKIN project, networks, regional nodes.

\footnotetext{
* Acknowledges: The result presented in this paper is part of the SKIN project (www.shortfoodchain.eu). This project has received funding from the European Union's Horizon 2020 Research and Innovation programme under grant agreement N. 728055.

** University of Foggia, Department of Economics, Largo Papa Giovanni II n. 1, Foggia 71121, Italy. Tel. 00390881781806.

*** University of Foggia, Department of Economics, Largo Papa Giovanni II n. 1, Foggia 71121, Italy. Tel. 00390881 781806. E-mail: fedele.colantuono@unifg.it.

**** University of Foggia, Department of Economics, Largo Papa Giovanni II n. 1, Foggia 71121, Italy. Tel. 00390881 781806. E-mail: sara.djelveh@gmail.com.

***** University of Foggia, Department of Economics, Largo Papa Giovanni II n. 1, Foggia 71121, Italy. Tel. 00390881 781806. E-mail: francesco.conto@unifg.it.
}

Rivista di Studi sulla Sostenibilità, (ISSN 2239-1959, ISSNe 2239-7221), 2017, 1 DOI: 10.3280/RISS2017-001011 


\section{Riassunto}

Sostenibilità economica nella filiera corta agro-alimentare. Il caso del progetto Horizon 2020 "Short Food Supply Chain Knowledge and Innovation Network (SKIN)"

Questo studio fornisce un metodo per individuare e diffondere le buone pratiche nell'ambito della filiera corta agroalimentare, in maniera tale che gli attori stessi possano fruirne. Una circolazione dinamica delle conoscenze consente la riduzione dell'asimmetria informativa tra tali operatori. Questi ultimi spesso lamentano un livello troppo alto dei costi di transazione, che incidono negativamente sulla sostenibilità delle loro aziende. Quindi, la loro riduzione è una priorità. L'approccio metodologico è affrontato nell'ambito del progetto SKIN, analizzando i parametri metrici per valutare la filiera corta agroalimentare. Si creerà una rete fatta di nodi regionali, tutti interconnessi tra loro, per la raccolta di buone pratiche. La rete permetterà un reale trasferimento e utilizzo delle innovazioni e della conoscenza. Infine, la rete sarà utilizzata per aumentare il valore aggiunto delle aziende coinvolte.

Parole chiave: sostenibilità economica, buone pratiche, filiera corta agroalimentare, progetto SKIN, reti, nodi regionali

\section{Introduction}

EC is putting in practice significant efforts to address policymakers toward a sharing resources-based idea to elaborate new local strategies. To validate such approach, EC have been involved groups of experts to analyze current and future European scenarios taking insights from a deepen stakeholders' needs analysis. The results have been issued with a 2014 report that shows the priority need to boost Open Innovation (OI) and Knowledge Transfer (KT). The report sets out to claim that it is necessary to build innovative markets, innovations hubs and networks. In particular, one of the main focus is on how firms develop collaborative approaches in using and combining internal and external resources. The assessment has to be considered in order to fulfil the final goal of returning a maximum added value from available intellectual property, in case it is not straight connected to the firms core business as well. Taking insights from such statements, an innovation cannot be seen as a single phenomenon not affecting the entire economic and social environment. Indeed, stakeholders get directly or indirectly involved in ecosystem challenges caused by pushing an innovation. These can include business entities, universities, intermediate public and private research organizations and, more in general, each one actively or passively holding interests. Networks will enable a real uptake of rural development fostering the creation of basic services that firms need to catch increasingly consumers 
(World Bank, 2016). The efforts have to be put in practice taking into consideration the innovative addresses of the Smart Specialization Strategy. It is intended as the milestone to identify the sector where to allocate resources and it indicates the method to involve local stakeholder and stimulate their participation to the European growth (Foray and Goenaga, 2013; Thissen, van Oort, Diodato and Ruijs, 2013; Foray, David and Hall, 2009).

\section{Literature Review}

The European Commission (EC) underpins strategies to promote local development establishing networks and spreading knowledge. Actors operating in European areas have to plan again strategies to implement locally, taking insights and feedback from global economic changes. To this extent, innovations, knowledge and networks play a fundamental role for developing local economies. The development can be achieved increasing the farm size (EC, 2015). In fact, in Europe there are many countries characterized by small-medium enterprises (SMEs). Small farms operating without cooperation suffer the deep and old problem of market asymmetry information (Reimann, Shen and Kaufmann, 2017). It causes an excessive level of transaction costs (TCs). In fact Tcs increase when asset specificity rises because of opportunism, defined by Williamson (1985) as "self-interest seeking with guile". Over the years, several studies (Klein, Crawford and Alchian, 1978; Williamson, 1985; Dyer, 1997; Libecap, 2014; Kelly, 2014) provide a clear explanation of the need to reduce asymmetric information through networks that enable innovation uptake and, in consequence, returning a reduction of transaction costs. These are composed as follows (Clemons et al., 1993):

Transaction costs $=$ coordination costs + transaction risks

Coordination costs are related to information into decision processes, including information on products, price, availability and demand. While, transaction risk is strictly related to the issue of asymmetry information In this regard, innovations are the result of knowledge application. In other words, they allow the transition of findings from researchers to entrepreneurs. Grover and Malhotra (2003) argue that transaction risk may loss of resource control and, in consequence, increase the risk of opportunistic behavior. Uncertainty caused by asymmetric information generates higher transaction costs. Furthermore, the Transaction Cost Theory (TCT), postulated by Williamson, is summarized by three propositions (Grover and Malhotra, 2003): the first one affirms that transaction costs are generated by bounded rationality and opportunism; the second one asserts that high asset 
specificity and high uncertainty gives rise transaction costs; the third one points out that governance mechanism determines higher or lower hierarchies. In particular, higher transaction costs favor the hierarchies. These are considered like those that mainly affect the increase of TCs by Williamson (1985). To this extent, networks can solve, or at least reduce, them. Within the markets, as well-known, there are two dimensions of the activities to manage the supply chain coordination: horizontal and vertical. The horizontal one intends all farmers typically competing each other. Benefits return them, whilst appears that gaining from pure competition is the only path to add value. The vertical one implies actors operating along the supply chain undergoing to different power positions. The outline of this scenario is based on the strategy to improve the added value of the supply chain reducing the costs, following one of the Porter' way to enhance the profitability of the agro-food sector in European areas. The Porter' differentiation strategy (Porter, 1985) states that existing methods to get the competiveness consist of the elements displayed in Porter' matrix (Figure 1).

Figure 1 - The Porter' matrix showing the factor influencing the firms competitiveness

Competitive advantage

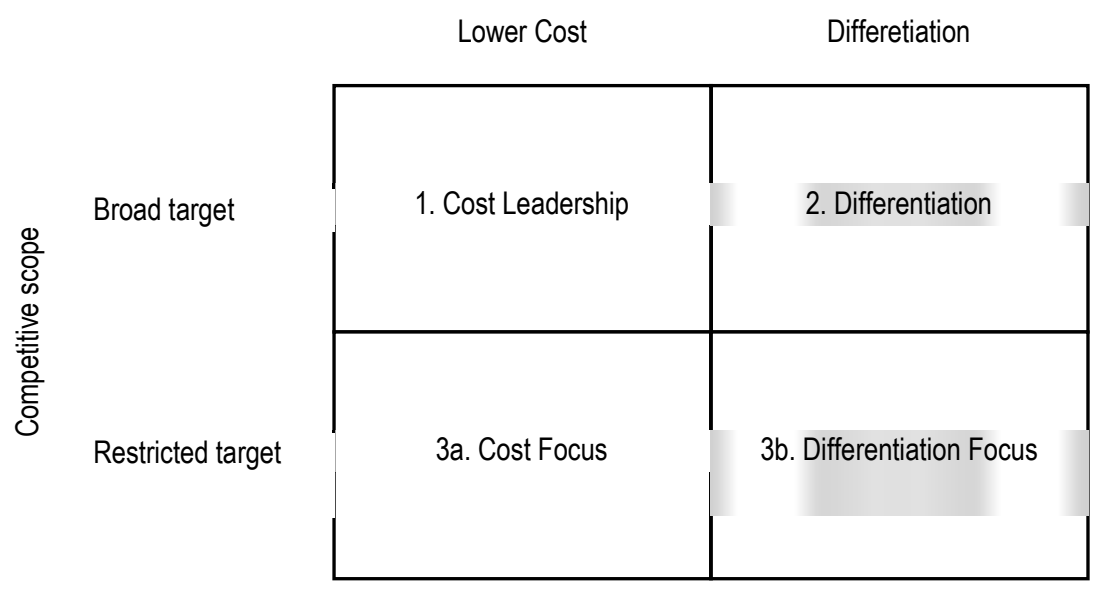

1. Cost Leadership: the firms takes benefits reducing the costs. To this extent, they are intended as TCs. The sources of cost advantage depend on the structure of the considered firm. Different types of costs benefits may come from property technology, economies of scale or others factors. The 
property technology case is strictly related to the purposes of this study in terms of the added value that firms potentially gain boosting innovation and knowledge transfer. The Cost Leadership advantage is exploited by the firm for leading the price within the industry.

2. Differentiation: the firm aims to be unique in the sector along some dimensions that are widely considered by buyers. The firm puts in practice efforts in order to identify one or more features perceived as relevant by as much as possible buyer, and makes itself unique respect to those attributes. The firm gains through a premium price acknowledged by purchasers for its uniqueness.

3. Focus: the firm restricts the attention and the attention to a specific target within his sector. The focuser selects a segment or a group of segments in the industry and fits its strategy to supply them excluding the others. The focus strategy shows two paths:

a. Cost focus: a firm seeks advantage cost in its restricted context;

b. Differentiation focus: a firm seeks its uniqueness within its target segment.

The differentiation taking the path of reducing costs is that aiming to be achieved through the reduction of TCs (Contò et al., 2013b). Such issues need to be managed through the involvement of as much players as possible, increasing the number and the kind of them. It means that farmers, advisors, researchers, NGOs etc. should actively participate to foster and underpin knowledge and information circulation. The cooperation has to be strongly raised by each one getting to become the basis of new cultural approach in competition game, named the multi-actor approach (AC, 2016). The latter explores the needs, and implies participatory acts finalized to share problems and relative solutions.

The Porter' competitiveness is in line with the main goals of the European Commission. In this regard, the effective plan Horizon 2020, based on the need of pursuing a sustainable, inclusive and smart growth, seeks to put in practice Porter' principles following different methods to implement daily firm' activities. Above all, in this article is shown a methodological approach, that is, in turn, based on the Focus Groups (EC, 2015) insights emerged after their work promoted by EC. Focus Groups (Levidow and Neubauer, 2014) are thematic, and composed by different stakeholders. Each stakeholder had to bring its contribute to the discussion in order to show the local needs and provide suitable and useful returns to the policy issued by EC. Furthermore, the afterwards explained methodological approach has been elaborated on the specific call identified as Coordination and Support Action (CSA). It has specifically planned to create condition to lead firms 
toward sustainable growing paths. The general framework consists in taking and showing existing knowledge and engaging collaborative approach among the actors to make smarter the economic system and add value to the food supply chain. The methodological approach has been thought and translated in real actions that have been implemented since SKIN project started in November 2016.

\section{Methodological approach, the case of "SKIN" project}

SKIN, acronym for Short supply chain Knowledge and Innovation Network, is the European thematic network on Innovative Short Food Supply Chain Management, funded by the European program H2020 (European Commission, EC, 2015; Sara and Francesco, 2016). The SKIN Project started in November 2016 and involves 20 partners from 14 countries in the area of short food supply chains (SFSCs), coordinated by the University of Foggia. The project is aimed at promoting an interactive innovative model to improve knowledge exchange between academia and practitioners of the management of SFSCs, thus contributing to reconnect EU food producers and consumers.

The SKIN project concerns the creation of a network on the theme of Short Food Supply Chains and will is aimed at satisfying EC requirements throughout different actions.

In the form of innovation projects for the application/adaptation of existing research results, as well as innovation projects exploiting ideas coming from stakeholders and addressed through the coaching activities organized. This will stimulate researchers to disseminate and implement their results in the agro-food sector.

As for the exchange of good practices, specific elements will be taken into account in order to combining productivity, competitiveness and sustainability in agriculture, with attention to the socio-economic impact on territories through the contribution to the development of rural areas in Europe and cooperation among the actors involved.

SKIN will organise and carry out the identification of about 100 good practices across Europe using the practice-abstract common format, and presenting them through the workshops, thus helping the generation of at least 10 innovation ideas to be supported through the coaching activities foreseen by the project.

The overall SKIN project approach is based on the need to systematise a pan-European knowledge base and its community of practice on the theme 
of short supply chains. Existing knowledge is highly fragmented into smaller, often regional or local communities, constituencies and experiences. So, these could be of benefit to agri-food communities at large, including supply chain actors, from producers to processors, distributors and retailers, if they were to be made easily accessible, shortening the distance between knowledge and its practical application in multi-actor communities.

The SKIN methodology is characterized by four elements, or pillars, as follows.

\section{First Pillar: Multi-Actor}

The multi-actor approach (Figure 2) is reflected not only in the structure and composition of the consortium but also in the engagement strategy foreseen in its work-plan, throughout dissemination and coaching activities.

A multi-actor approach in SKIN is thereby an inclusive approach oriented to consider the role and perspectives of different players.

Thanks to the definition of the engagement strategy that will identify actors, methods and opportunities to aggregate around SKIN, a large and representative, multi-party community of stakeholders from as many countries and regions possible in the EU and associated countries will be involved.

To summarize, SKIN multi-actor approach is based on four elements that characterize the consortium:

1. the presence within the consortium of partners with complementary types of knowledge and skills;

2. the strategy developed and implemented to involving actors from the broad community of short food supply chains at different regional scale (regional nodes), as well as at the international level (transversal sub-thematic workshops);

3. the methods utilized to ensure quality and quantity of knowledge exchanges;

4. the realization of a structured organization and management all along the project. 
Figure 2 - The Multi-actor approach

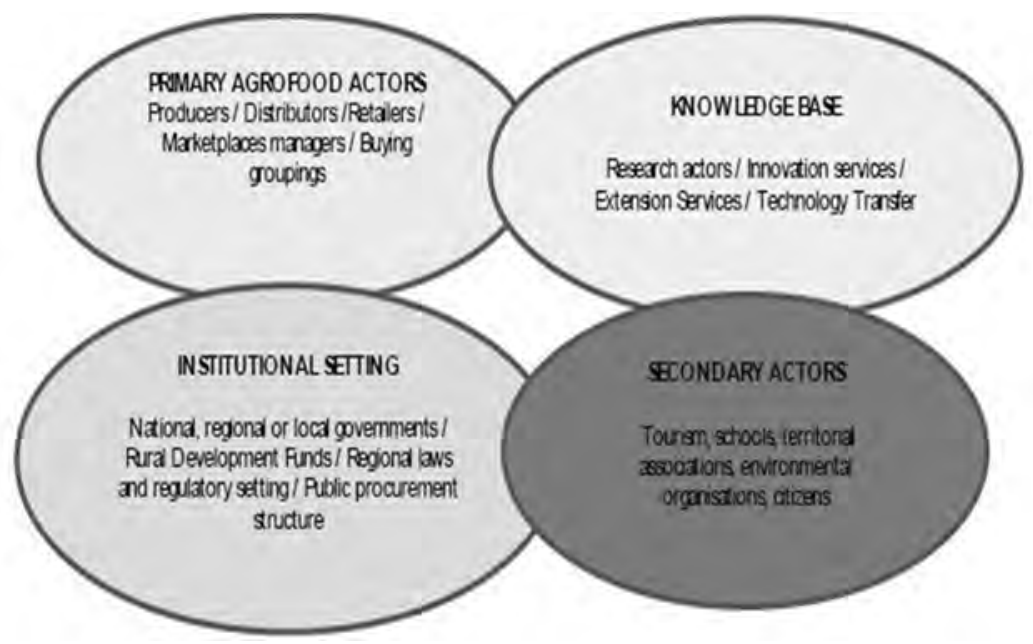

Second Pillar: Multiplication of exposure to the research base, good practices and innovation opportunities

One of the key drivers of the project is to deliver information and knowledge to those that need it across the EU, essentially through two complementary approaches from good practices to innovation projects. In particular, the systematization of information and data on good practices for short food supply chains (identified through an extensive mapping in different countries) and the organization of regional technical nodes (composed by territorial-based multi-actors partnerships), will provide the basis for coordinating the SKIN activities at different regional levels. The coordination of activities at regional levels, through the regional nodes, will help capturing demand-driven innovation needs and opportunities from the different territories involved in SKIN, thus allowing the tailoring of the innovation to different contexts.

On the other hand, the organization of thematic workshops addressed to concrete innovation challenges, will possibly entail the exchange of those good practices or new approaches to innovating short supply chains.

Moreover, through online tools, the target communities may consult cooperation profiles, set up partnerships oriented to new innovation projects and access information in multiple languages in the form of easy accessible 
end-user materials. Such materials will be realized and targeted in compliance with the SKIN dissemination strategy, thus according to the principles of: accessibility, broadness, standardization, openness and sustainability.

\section{Third Pillar: Practical experience, practical guidance}

Since SKIN is a practice project, it will be considered a successful initiative if a wider number of SFSC actors will participate in the adoption of results of innovation driven research projects, or will take part in concrete projects with the support of SKIN coaching services. In this light, it is important to identify and bring to practitioners good practices that have significant potential, with concrete guidance on the possible adaptation of those good practices to their specific needs in order to promote effective knowledge exchange and cooperation with interested parties, as well as providing practical guidance (coaching phase) to those wishing to set up innovation projects.

\section{Forth Pillar: Permanent network}

Given the deep knowledge-fragmentation about SFSC, a coherent framework for cooperation around supply chains should be established, and reflected in the organization of a community of practice that will remain after the end of the project. According to this, SKIN intends to provide the European SFSCs with framework of reference for access to research and innovation advances, a mechanism to foster cross-border partnerships for the uptake of innovative practices and research results, plus a growing network of experts and stakeholders able to contribute both on a research and policy level in different EU territories.

SKIN integrates coordination and support activities within the four pillars that constitute its overall approach, mainly related to community building and knowledge sharing activities.

\section{Discussion and Conclusion}

The preliminary analysis provided in the introduction concerns the conceptual idea proposed by European institution and stakeholder indicating prerequisites and desired goals. Conversely, the showed methodological approach is a real application plan to whom EC agreed to finance. The EC approved the explained proposal and allocated resources to it. There, immediately, emerge two deductions, before going deepen to the economic implications occurring with such circumstance. Firstly, the outline of the project is 
in line with the aforementioned prerequisites and so, it goes satisfying the outcomes desired. It gets closer the innovation gap between research and practice. Secondly, it makes to feel responsible European stakeholders through their active involvement within the growth path. The Smart Specialization Strategy pursued by local government, is mainly focused on the idea to actively involve as much as possible stakeholder to initiate putting in practice efforts. It fulfills a social sustainability dimension indicated as inclusive approach. The topic of the project is the Short Food Supply Chain (Berti, \& Mulligan, 2016) and following the addresses of the SSS, it is relevant due to many European area are characterized by different organizational features within the Food Supply Chain. The differences arise problems that operators cannot individually manage. In particular, Mediterranean areas suffer the geographic peripheral position in European scenario and they need to implement efficient and successful method to get northern markets. To analyse such aspects and collect detailed information about the needs of the actors involved and to be involved in the project, there have been organizing online and non-online meeting. For example, from the already done meeting has appeared that there is a different meaning of the length of short food supply chain. Such difference hides prominent issues, concerning logistics knowledge that cannot be exploited everywhere, though they are going to be qualified as good practice. Therefore, the strongest challenge is to find the way to harmonize different features, seeking to combine rightly elements of each one with each other. Being aware of this risk, the multi-actor approach appears as indispensable. Indeed, according to the methodological framework provided, it plays a key role in reducing the asymmetric information among the economic operators. It also allows better understanding the European markets with high potential growth. Reducing the information gap makes operators much more collaborative and able to engage vital synergies. The Porter' idea to make competitive the firms through the differentiation of segments, costs or other attributes is substituted by the idea to improve the competitiveness of entire economic system (Gobble, 2016). The original purpose was aimed to return local benefits single firm. The current approach returns benefits to as much as possible actors. It is a prominent aspect for rightly facing the market globalization and for better allocate the available resources reducing wastefulness. In SKIN, the idea to treat the topic of the SFSC is strictly related to the higher level of sustainability that reach such method to organize the FSC (Fiore, 2016). In this regards, SSC is an acknowledged method to reduce the asymmetric information and, in turn, TCs (Williamson, 2008). Getting closer producers to consumers, each one gets to be much more aware and able to take rational decisions. However, 
many regions were stressed by economic crisis and they have appeared not able to cope it. A consistent issue of the farmers is that they often are not able to find and adopt suitable and innovative technologies. The concerns are related to the methods looking for new markets, the adoption appropriate innovation to decrease the resources uses etc. All these things are grouped in with the difficult of finding them in time or with an affordable price. The natural consequence is the high level of TCs, appearing in both forms of coordination costs and transaction risk. The need of new technologies have been confirmed by a World Bank study (2016). For example, the study clearly shows as the adoption of internet devices significantly allows reducing TCs (Figure 2). The majority areas that suffer the lack of innovation in terms of adoption of new ICT based tools are located in southern peripheral countries. In addiction, although getting innovative digital resources is a prominent progress, there is a lack of infrastructures, restricting the opportunity and the potential of the innovation (World Bank, 2016).

Figure 3 - The effects of falling TCs

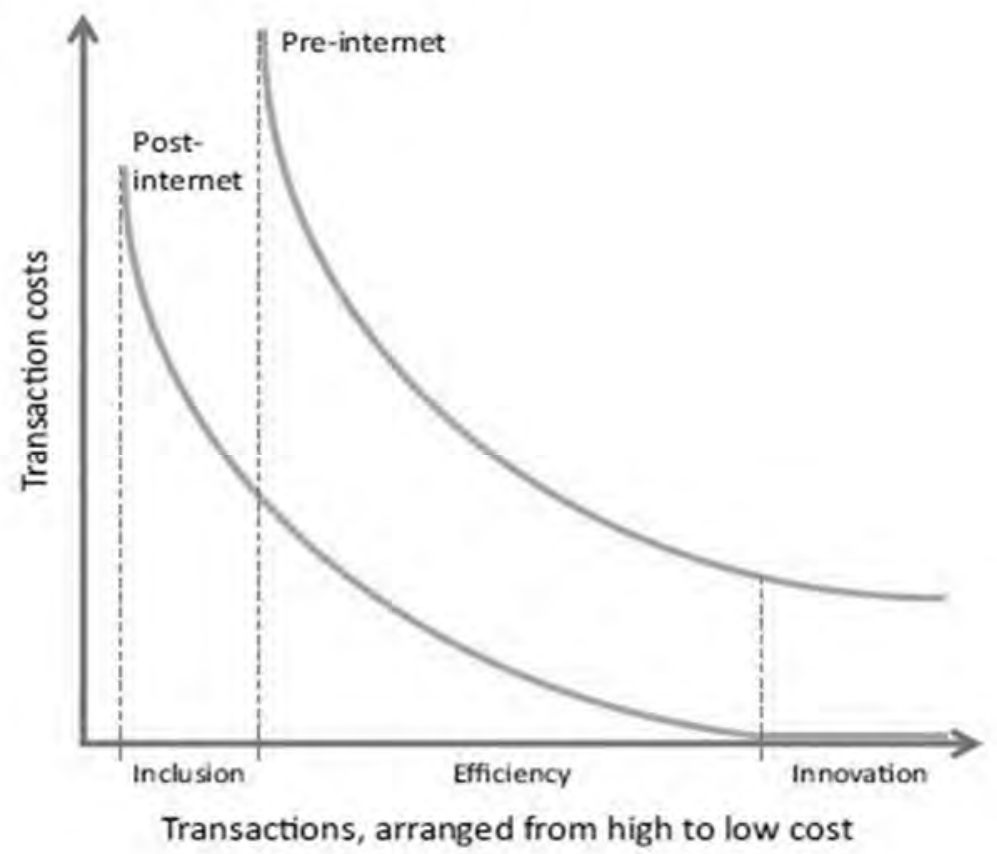

Source: World Bank (2016). 
The picture shows that the effects of falling TCs due to digital technologies, determine benefits in terms of (World Bank, 2016):

- Inclusion: because of overcoming information barriers, it is possible to get inclusion and, in turn, the opportunities increase, triggering a job creation process;

- Efficiency: because of augmenting existing factors, there appear an increasingly efficiency, which determines, in turn, an increasingly labour productivity;

- Innovation: because of generating economies of scale from innovation uptake, it is possible to obtain a consumer surplus, resulting as a benefit in terms of price.

Through SKIN project, it will be collected good practices characterized by innovative systems. The main features of such practices will be stored in a database to whom each operators involved in the building consortium will be able to access in real time, taking any date it needs. The knowledge and best collected experiences of each European area will be managed by local hubs concentrating knowledge and experts capable to reply efficiently to actors asking for advices. Regional nodes will be connected each other in order to return innovation circulation and real uptake. Each participant to the consortium will get benefits in terms of productivity, profitability and marketplaces. The lack of infrastructure can be compensated by building network implementing digital technologies and bringing together expertise to recognize solutions. In conclusion, EC approved the SKIN project as a result of a whole of factors that enables the actors of the supply chain to get more and more closer in order to pursue an horizontal and vertical integration through the entire agro-food sectors, avoiding further fragmentation, being the principal reason of the low export market volume of a consistent number of SMEs actives in European countries.

\section{References}

Berti G., Mulligan C. (2016). Competitiveness of Small Farms and Innovative Food Supply Chains: The Role of Food Hubs in Creating Sustainable Regional and Local Food Systems. Sustainability, 8(7): 616.

Contò F., Faccilongo N., La Sala P., Dicecca R. (2013a). Cloud approach for short chain administration. Procedia Technology, 8: 600-605.

Contò F., Fiore M., La Sala P. (2013b). The role of innovation in the integrated processes of Integrated Project of Food Chain: the case of cherry cultivation chain in Apulia region. Intellectual Economics, 7, 4(18): 467-485. 
European Commission, EC (2015). EIP-AGRI Focus Group Innovative Short Food Supply Chain management, Final report.

European Commission, EC (2015). Calls for proposals and related activities under the 2016-17 work programmes under Horizon 2020 - the Framework Programme for Research and Innovation (2014-20) and under the Research and Training Programme of the European Atomic Energy Community (2014-18) complementing Horizon 2020. Official Journal of the European Union (2015/C 399/02).

Fiore M. (2016). Direct selling in the wine sector: lessons from cellars in Italy's Apulia region. British Food Journal, 118(8).

Foray D., David P.A., Hall B. (2009). Smart specialization - the concept. Knowledge Economists Policy Brief, 9(85): 100.

Foray D., Goenaga X. (2013). The goals of smart specialisation. Luxembourg: Publications Office of the European Union.

Gobble M.M. (2016). News and Analysis of the Global Innovation Scene. ResearchTechnology Management, 59(3): 2-9.

Kelly P.J. (2014). Information efficiency and firm-specific return variation. The Quarterly Journal of Finance, 4(04): 1450018.

Levidow L., Neubauer C. (2014). EU research agendas: Embedding what future? Science as Culture, 23(3): 397-412.

Libecap Gary D. (2014). Addressing Global Environmental Externalities: Transaction Costs Considerations. Journal of Economic Literature, 52(2): 424-479(56), June.

Reimann F., Shen P., Kaufmann L. (2017). Multimarket Contact and the Use of Power in Buyer-Supplier Relationships. Journal of Business Logistics.

Sara D., Francesco C. (2016). University knowledge exchange and the SKIN Project. Research on Education and Media, 8(2): 33-41.

Thissen M., van Oort F., Diodato D., Ruijs A. (2013). Regional Competitiveness and Smart Specialization in Europe: Place-based development in international economic networks. Edward Elgar Publishing.

Williamson O.E. (2008). Outsourcing: Transaction cost economics and supply chain management. Journal of Supply Chain Management, 44(2): 5-16.

World Bank (2016). World Development Report 2016: Digital Dividends, World Bank, Washington, D.C. 